\title{
PATHWAYS IN REAL-LIFE LEARNING
}

\section{The road to expertise}

\author{
Julia Walsh and John Cripps Clark \\ Faculty of Education, Deakin University, Burwood, Australia \\ jwalsh@deakin.edu.au and john.crippsclark@deakin.edu.au
}

\begin{abstract}
The pathway to expertise is a long journey, and few make it. Regardless of discipline, the journey is similar; what differentiates the journey is the knowledge that underpins the profession. This research explores expert teachers and the knowledge that underpins the teaching profession. Much research in teacher education has concentrated on individual elements of expert teaching. There has been less emphasis on understanding the complex real-life process of expert teaching in its entirety. The model presented here looks at an integrated approach to understanding the development of expert teachers through real-life learning experiences and related factors
\end{abstract}

Key words: Expertise, higher education, practicum.

\section{INTRODUCTION}

In teacher education, pathway planning enables pre-service teachers to situate themselves in the field, to monitor their progress, and to understand and organise their knowledge. This is only possible when understanding of what knowledge underpins the profession, the relationship between the knowledge domains, and how the different knowledge domains mature. This paper discusses an emerging evidence-based model of the 'expert teacher'. The model emphasises not only the usual elements of effective teaching content knowledge, pedagogical knowledge and pedagogical content knowledge - but also takes into account the teacher's personal knowledge and knowledge of context, both of which are derived from real-life learning experiences. We suggest that it is not just this knowledge that teachers have in these domains but the way this knowledge overlaps and interacts both 
within the teacher and with the teacher's physical, social, intellectual and emotional environment. An examination of the expert teacher through the use of this model challenges us to rethink the way we educate both preservice and in-service teachers and the way we assess, judge and reward teachers. It highlights the important role of real-life learning in the development of expertise and the need to accommodate it more robustly in Teacher Education programmes.

This study arose from our individual $\mathrm{PhD}$ research, which involved in depth interviews with primary science teachers (Cripps Clark) and elite sports coaches (Walsh). It emerged that these two very different groups of highly effective teachers - the coaches were overwhelmingly also teachers were remarkably similar.

Common features that emerged, were:

- strong discipline content knowledge;

- pedagogical skills appropriate to the environment and discipline;

- personal knowledge which included: the ability to forge strong relationship with the students, a concern for individual students and a firm moral code.

- intimate knowledge of the context in which they were teaching.

We have used these components to develop a prototype model and then refined this model using observations and interviews with a more diverse sample of expert teachers.

\section{WHAT IS AN EXPERT TEACHER?}

The pathway to expertise is a slow process that few achieve. A number of lines of evidence have been used to identify expert teachers including: certification, results their students achieve, peer assessments, students or the community, the classrooms they establish, and their status in the profession. Shulman (1987) distinguishes between pragmatic effectiveness measured by correlation, usually with student academic achievement measures, and normative effectiveness measured by correspondence, usually with a model or conception of good teaching. Our study is inherently normative but builds on the data from pragmatic studies.

\section{THE NEED FOR A MODEL}

A model must simplify the representation of complex phenomena, making the abstract concrete, without masking essential elements that are needed to generate explanations and to interpret observations. This model is 
an attempt to create a coherent map of expert teachers so that our analysis can go beyond a mere checklist of attributes or behaviours. It attempts to provide a language for discussing not just the knowledge that expert teachers possess but also the way in which this knowledge interacts in formal and real-life learning, professional contexts, and pathway planning.

\subsection{The Components of a Model}

We have identified four clusters of knowledge domains: content (discipline) knowledge, pedagogical knowledge and skills, and knowledge of context and personal knowledge. Pedagogical content knowledge (PCK) is the intersection of discipline knowledge and pedagogical skills. The other intersections include such elements as: the teacher's personal epistemology; the teacher's knowledge of curriculum and their students; and the relationships that the teacher forges with colleagues and students.

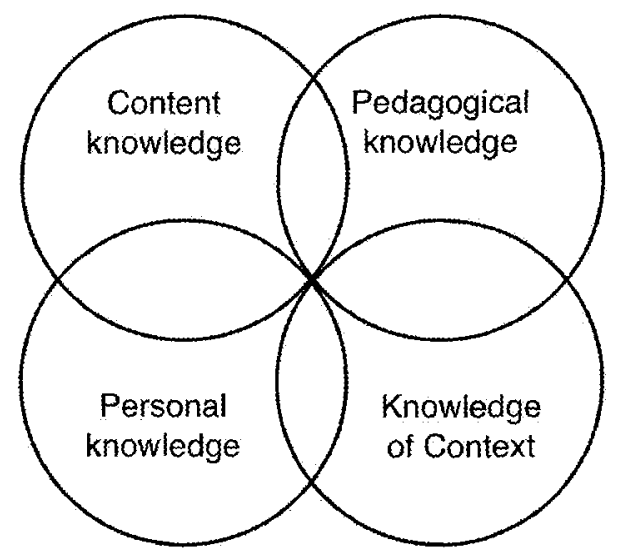

Figure 1. Foundation for a model of effective teachers

\subsection{Discipline Knowledge}

Often the public debate about teachers and teaching standards is reduced the claims of inadequate discipline knowledge. The question of the range and depth of discipline knowledge teachers need for students of differing maturity is accentuated by what is perceived as a time of rapid increase in knowledge in most disciplines. Discipline knowledge encompasses an understanding of the salient concepts, relations among concepts, ideas and skills of a subject (Shulman, 1987) and has always been acknowledged as 
the first prerequisite of ability to effectively teach a discipline. Teachers are often described in terms of a specific discipline knowledge.

Discipline knowledge is a necessary component of most theories of teaching whether they are traditional transmission models, constructivism or even behaviourist. This discipline knowledge is usually a significant part of a teacher's education. Research investigating discipline knowledge in teaching has examined the difference between novice and expert teachers in how they store, access and use specific discipline knowledge. The expert teacher is more likely to create mental models based on a problem solving approach and attach deeper meaning and extract more information from the environment in a more significant way. Discipline knowledge is also a crucial prerequisite in the development of teacher self-confidence. Understanding and being able to apply discipline knowledge builds selfconfidence, and self-confidence is crucial in the development of an expert teacher.

Although discipline knowledge is an expectation, when it comes to choosing and judging teachers it is the combination of discipline knowledge, application, interpersonal skills and motivational style that is valued. There is also an increasing realisation that discipline knowledge and pedagogical skill are inextricably linked and cannot be taught independently.

\subsection{Pedagogical Skills}

With the rise of professional teachers - rather than the tradition of practitioners who apprenticed students, notably with the Sophists in classical Greece (Beck, 1996) - the distinction between the practice of a discipline and the teaching of the discipline gave rise to the notion of skills and knowledge independent of the discipline and particular to teaching. This art and science of teaching became known as pedagogy. Berliner (1991) defines pedagogical knowledge as consisting primarily of knowledge about classroom management, the organization of classrooms, assessment, methods for the motivation of students, personal knowledge about particular students and their families, and social-interactional skills. Research investigating expert teachers verifies that pedagogical expertise resembles expertise in other fields, is a very sophisticated form of knowledge that is not easily gained or mastered, and not available to everyone that seeks it (Berliner 1991)

There remains however a tension over the separation of the categories of discipline and pedagogical knowledge. Lusted (as cited in Tinning, MacDonald, Wright, \& Hickey, 2001) proposed that how one teaches cannot be separated from how one learns and the nature of the subject matter. Therefore instruction cannot be separated from learning or curriculum. 
Berliner (1991) postulates that to study pedagogy independent of discipline knowledge is to miss something of the intimacy of the relationship. He also draws attention to the question of low transfer of pedagogical skills across disciplines. Tytler (2002) has pointed out that the learning of new discipline knowledge is of itself a pedagogical exercise. Different subjects have different epistemologies, hence an expert physical education teacher is not automatically going to transfer their expertise into the teaching of English. In each field there are also specific and explicit and implicit prescriptions and proscriptions of behaviour for teacher and student.

The separation of pedagogical skills and personal qualities is also artificial. Taking a more people centred view, Van Manin (1994) describes pedagogy as the relational knowledge of children, that one understands children and youths: how young people experience things, what they think about, how they look at the world, and how each child is a unique person. He also notes that neither the European nor the North American scholarship of teaching seems to have fully explored the significance of the 'pedagogical relation' for the practice and teaching of learning. In this description the relationship between the teacher and the student is paramount. The teacher establishes the relationship with the student, cares for the student by caring for what they may become, and makes adjustments to their interactions based on the situation and experiences of the student. For the student the teacher provides opportunities for heightened experiences, a sense of self, and a real growth and personal development.

\subsection{Knowledge of Context}

The classroom, school culture, community, educational system and students can all significantly influence the effectiveness of a teacher. A teacher who may be an expert in one context may struggle in another. Any model of teaching expertise must be situationally contingent (Locke, 1991). Any theory of contingency will need to involve such factors as the volatility of the environment the discipline taught, the community, the school and departmental organisation and philosophy and the backgrounds of the students. As the context changes the weight or degree of importance accorded to the various components of teacher knowledge may vary rather than the components themselves. Thus in a highly academic environment discipline knowledge becomes more important while for marginalised students, personal qualities come more to the fore. 


\subsection{Personal Knowledge}

Van Manin (1994) describing expert teachers, states that what we receive from a great teacher is less a particular body of knowledge or set of skills, than the way in which this subject matter was represented or embodied in the person of this teacher; his or her enthusiasm, self discipline, dedication, personal power, and commitment - characteristics which draw strongly on many aspects to the teacher's real-life learning experiences.

The teacher's personal qualities are recognized as being influential in the overall picture of an expert teacher. Two components of personal qualities are: a moral code of behaviour such as honesty, and integrity, and the teacher's personal philosophy and self-belief, which is best described within a motivational framework. Understanding the role personal qualities play and how they interact with other characteristics of effective teaching addresses and provides insight into the "who question" which Zembylas (2000) claims has been ignored in research on expert teachers. The behaviours most cited as reflecting expert teaching and leadership are honesty, and integrity (Locke, 1991). In combination these behaviours provide the foundation for a trusting relationship between the teacher and his or her students.

Expert teachers and leaders are driven by a strong and coherent philosophy, and influenced by their self-efficacy beliefs. Not unexpectedly these teachers reveal a holistic philosophy that centres on educating students for life. These teachers also have positive self-efficacy beliefs and are comfortable with innovation and risk taking (Gibbs, 1999). Self-efficacy beliefs are powerful predicators of behaviour and explain the choices people make, their aspirations and persistence in difficult situations (Bandura 1977, 1982). Developing positive self-efficacy beliefs is a slow process built up over time through experience, exposure and a deeper understanding of self.

\section{THE EMBEDDED NATURE OF KNOWLEDGE}

Teachers' knowledge does not exist in isolation-it is part of a greater shared knowledge and practice with which they have a continuing dialogue. Fig. 2 is an attempt to locate it within teachers' physical, social, intellectual and emotional environments. Thus the content knowledge is but a subset of the whole discipline knowledge and forms (albeit a small) part of it. The pedagogical knowledge is intrinsically bound to the community of practice that the teacher contributes to. Context knowledge exists in a continual dialogue with the actual context: classroom, school and community. Their personal knowledge is bound into their relationship with those they relate to. 


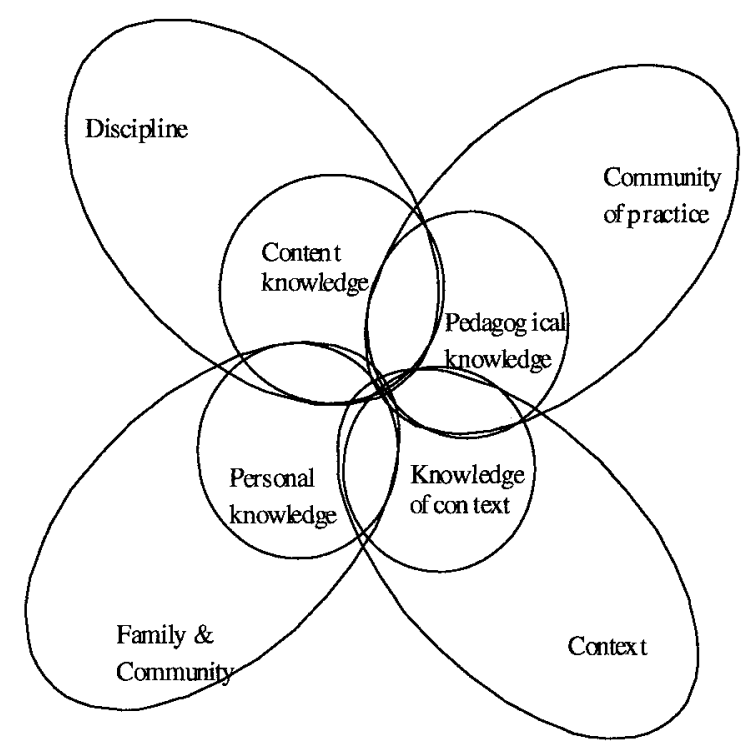

Figure 2. Embedded knowledge model

\section{DYNAMICS}

This model is not just a way of conceptually organising the checklists that are normally given to describe expert teachers. Knowledge and skills exists in real human beings not in isolation and thus interacts both within the teacher and with the teacher's intellectual, social, emotional and physical environment. This model provides a basis for discussing and analysing these interactions in specific teachers.

\section{CONCLUSION}

Real-life learning is dependent on opportunities for engaging with knowledge, the manipulation and the application of knowledge, and the capacity to deal with complexity. Developing teaching expertise is about real-life learning. In teaching, the pathway to expertise, as identified by this research, is a slow developmental process. Four knowledge domains underpin teaching expertise, with each knowledge domain maturing at a different rate. During the early stages of teacher education students engage 
with the theory, have opportunities to apply their knowledge in the field, and with deliberate experience develop the capacity to deal with complexity. The evidence-based model presented in this research provides a way of thinking about the development of teacher expertise. There is a tendency to expect pre-service teachers to make sense of their education. This model provides a pathway or road map to assist pre-service students in understanding their journey with a pathway, and course architecture designed to develop appropriate domain knowledge.

\section{REFERENCES}

Bandura, A. (1977). Self-efficacy: toward a unifying theory of behavioural change. Psychological Review 84, 91-215.

Bandura, A. (1982). Self efficacy mechanisms in human agency. American Psychologist $37(2), 122-147$.

Berliner, D. (1991). Educational psychology and pedagogical expertise: New findings and new opportunities for thinking and training. Educational Psychologist 2: 145-155.

Garrison, J. (1997). Dewey and eros: Wisdom and desire in the art of teaching. New York, Teachers College Press.

Gibbs, C. (1999). Believing, thinking and feeling: Putting the teacher back into effectiveness. Joint Conference of the New Zealand Association for Research in Education and Australian Association for Research in Education, Melbourne.

Justi, R. \& J. Gilbert (2002). Modelling, teachers' views on the nature of modelling and implications for the education of modellers. International Journal of Science Education 24(4): 369-387.

Locke, E. A. (1991). The essence of leadership. New York, Macmillan.

Loughran, J. (2001). A methodological maze: Attempting to capture pedagogical content knowledge. Contemporary Approaches to Research in Mathematics, Science, Health and Environmental Education 2001, Deakin University, Burwood: CSMEE.

Raban, R. (2002). Work based learning partnerships. Experiential learning workshop, 56/3/02, Deakin University, Geelong.

Shulman, L. S. (1987). Knowledge and teaching: Foundations of the new reform. Harvard Educational Review 57(1): 1-22.

Tinning, R., D. MacDonald, et al. (2001). Becoming a physical education teacher: Contemporary and enduring issues. Sydney, Prentice Hall.

Tytler, R. (2002). personal communication, Melbourne.

Van Manin, M. (1994). Pedagogy, virtue and narrative identity in teaching. Curriculum Inquiry 24(2), 135-170.

Zembylas, M. (2000). Emotions and elementary school teaching. University of Illinois. 